\title{
Impact of food, alcohol and pH on modified-release hydrocortisone developed to treat congenital adrenal hyperplasia
}

\author{
Nayananjani Karunasena', Daniel N Margetson², Greg Neal', Martin J Whitaker² \\ and Richard JM Ross ${ }^{1}$ \\ ${ }^{1}$ Department of Oncology and Metabolism, University of Sheffield, Sheffield, UK and ${ }^{2}$ Diurnal Limited, \\ Cardiff, UK
}

\author{
Correspondence \\ should be addressed \\ to R Ross \\ Email \\ r.j.ross@sheffield.ac.uk
}

\begin{abstract}
Background: We developed a modified-release hydrocortisone, Chronocort, to replace the cortisol rhythm in patients with congenital adrenal hyperplasia. Food, alcohol and pH affect drug absorption, and it is important to assess their impact when replicating a physiological rhythm.

Subjects and methods: In vitro dissolution to study impact of alcohol and $\mathrm{pH}$ on Chronocort. A phase 1, three-period, cross over study in 18 volunteers to assess the impact of food on Chronocort and to compare bioavailability to immediate-release hydrocortisone.

Results: In vitro dissolution of Chronocort was not affected by gastrointestinal pH up to 6.0 nor by an alcohol content up to $20 \% \mathrm{v} / \mathrm{v}$. Food delayed and reduced the rate of absorption of Chronocort as reflected by a longer $\mathrm{T}_{\max }$ (fed vs fasted: $6.75 \mathrm{~h}$ vs $4.5 \mathrm{~h}, P=0005)$ and lower $C_{\max }(549.49 \mathrm{nmol} / \mathrm{L}$ vs $708.46 \mathrm{nmol} / \mathrm{L}$, ratio $77 \%$ with $\mathrm{Cl} 71-85)$. Cortisol exposure was similar in fed and fasted state: Geo LSmean ratio (CI) AUC $\mathrm{C}_{0 \mathrm{t}}$ for fed/fasted was $108.33 \%$ (102.30-114.72\%). Cortisol exposure was higher for Chronocort compared to immediate-release hydrocortisone: Geo LSmean ratios (CI) 118.83\% (111.58-126.54\%); however, derived free cortisol showed cortisol exposure Cls were within 80.0-125.0\%: Geo LSmean ratio (Cl) for $\mathrm{AUC}_{0 \mathrm{t}} 112.73 \%$ (105.33-120.65\%).

Conclusions: Gastric $\mathrm{pH} \leq 6.0$ and alcohol do not affect hydrocortisone release from Chronocort. Food delays Chronocort absorption, but cortisol exposure is similar in the fasted and fed state and exposure as assessed by free cortisol is similar between Chronocort and immediate-release hydrocortisone.
\end{abstract}

\section{Introduction}

Cortisol has a distinct circadian rhythm with low levels at night, rising in the early hours of the morning, peaking on waking and declining over the day to low levels in the evening (1). Current immediate-release hydrocortisone therapy cannot replace this circadian rhythm; patients take twice or thrice daily hydrocortisone, and despite this, cortisol levels are suboptimal in many patients with adrenal insufficiency (2). This is a particular problem in patients with adrenal insufficiency due to congenital adrenal hyperplasia who have poor health outcomes
(3). To address this, a number of technologies have been developed including hydrocortisone infusions (4), and modified-release formulations of hydrocortisone; Plenadren a once-daily modified-release hydrocortisone (5), and Chronocort a delayed and sustained absorption modified-release hydrocortisone that replicates the overnight profile of cortisol (6).

Food influences the absorption of immediaterelease hydrocortisone; delaying and increasing the variability of the $\mathrm{C}_{\max }$, prolonging the absorption
C 2017 The authors Published by Bioscientifica Ltd. Printed in Great Britain

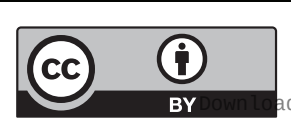

This work is licensed under a Creative Commons Attribution 3.0 Unported License. 
half-life and decreasing oral clearance (7). Cortisone when taken with food shows an increased cortisol $\mathrm{C}_{\max }$ and AUC; however, this was not considered to be clinically significant (8). In adrenal insufficiency, cortisol levels are low on waking at a time when they should be highest so most clinicians recommend taking hydrocortisone on waking although many patients will take food shortly afterward (7). The impact of food on modified-release formulations of hydrocortisone is likely to depend on the type of formulation developed. Plenadren is a dual release tablet with an immediate release coating and extended release core (5). Plenadren is recommended to be taken before breakfast and in the fasted state has approximately $20 \%$ lower bioavailability compared to immediate release hydrocortisone based on the AUC of cortisol (9). Plenadren taken with food shows similar changes to those seen with immediate-release hydrocortisone with a delayed $\mathrm{C}_{\max }$ and an approximately $30 \%$ increase in AUC (10). Chronocort is a multi-particulate formulation that has a pH-dependent delayed release coating that allows for delayed release and sustained absorption (6). This manuscript reports the in vitro impact of alcohol and $\mathrm{pH}$ on the release of hydrocortisone from Chronocort, the in vivo impact of food on the pharmacokinetics of Chronocort and compares bioavailability to immediaterelease hydrocortisone.

\section{Materials, methods and subjects}

\section{In vitro dissolution studies of $\mathrm{pH}$ and alcohol}

An in vitro dissolution methodology using rotating basket USP apparatus 1 (Sotax AT7 smart system) was developed to best represent the expected dissolution conditions in vivo. Briefly, dissolution vessels were filled with $700 \mathrm{~mL}$ of USP-simulated gastric fluid ( $\mathrm{pH} 1.2$ ) and pre-warmed to $37 \pm 0.5^{\circ} \mathrm{C}$. In separate vessels, sufficient buffer to adjust the $\mathrm{pH}$ of the media was pre-warmed. Chronocort (5 or $20 \mathrm{mg}$ hydrocortisone) capsules were added to each basket and once the media was at the required temperature, they were lowered into the media, with the rotating speed set to $100 \mathrm{rpm}$. At $30-\mathrm{min}$ intervals, $1-2 \mathrm{~mL}$ of sample was collected for analysis. The samples were vialled neat for analysis. The amount of hydrocortisone dissolved in the media was determined by HPLC analysis (Agilent 1100/1200 system) using reverse-phase chromatography with UV detection at $254 \mathrm{~nm}$. The impact of gastric conditions and alcohol concentration on Chronocort was evaluated by dissolution testing under three different study conditions:
1. $\mathrm{pH} 1.2$ for $0.5 \mathrm{~h}, \mathrm{pH}$-change to 4.5 for $2.5 \mathrm{~h}, \mathrm{pH}$-change to 7.2 for $1.5 \mathrm{~h}$.

2. $\mathrm{pH} 4.5$ for $3 \mathrm{~h}, \mathrm{pH}$-change to 7.2 for $1.5 \mathrm{~h}$.

3. $\mathrm{pH} 1.2$ for $2 \mathrm{~h}, \mathrm{pH}$-change to 6.0 for $1 \mathrm{~h}, \mathrm{pH}$-change to 7.2 for $1.5 \mathrm{~h}$. All media were mixed with alcohol (ethanol) to produce a concentration of $5,10,20$ or $40 \% \mathrm{v} / \mathrm{v}$ alcohol.

Calculation of dissolution profile comparison by $f_{2}$ test was carried out according to the following formula:

$$
f_{2}=50 \cdot \log \left\{\left[1+(1 / \mathrm{n}) \Sigma_{t=1} n\left(R_{t}-T_{t}\right)^{2}\right]^{-0.5} \cdot 100\right\}
$$

where $R_{t}$ and $T_{t}$ are the cumulative percentage dissolved at each of the selected number $(n)$ of time points of the reference dissolution profile and test dissolution profile respectively. Two dissolution profiles are considered similar when the similarity factor $\left(f_{2}\right)$ value is $>50$.

\section{In vivo pharmacokinetic studies fasted, fed and relative bioavailability}

Human studies were undertaken at Simbec Research Ltd (Merthyr Tydfil, UK). Eighteen healthy male volunteers, mean age of 34 years (s.D. 9.3) and mean BMI of $24.91 \mathrm{~kg} / \mathrm{m}^{2}$ (s.D. 1.8) participated in this open label, randomized, single-dose, three-period, cross over, single center, phase 1 study (www.clinicaltrials.gov trial NCT02408068). The primary objectives of the study were to compare the pharmacokinetics of Chronocort under fed and fasted conditions at a single dose of $20 \mathrm{mg}$ and to evaluate the relative bioavailability of Chronocort and immediaterelease hydrocortisone. The three periods were Chronocort $20 \mathrm{mg}$ in fed state $(30 \mathrm{~min}$ after the start of a high-fat, high-calorie diet), Chronocort $20 \mathrm{mg}$ in fasted state (10-h overnight fast) and hydrocortisone $20 \mathrm{mg}$ in fasted state (10-h overnight fast). A minimal washout period of 7 days was ensured between each study period. Seventeen subjects completed the study, one subject was withdrawn due to treatment emergent adverse events (TEAE) after oral dexamethasone administration.

In study periods 1 and 2 (Chronocort $20 \mathrm{mg}$ in fed state and fasted state) dexamethasone-suppressed subjects (1 $\mathrm{mg}$ dexamethasone administered at $22: 00 \mathrm{~h}$ on Day 1, and at $\sim 06: 00, \sim 12: 00, \sim 18: 00$ and $\sim 22: 00$ h on Day 1) were admitted to the clinical unit on the previous day and remained until completion of all procedures (i.e. $24 \mathrm{~h}$ after dose). During the fed study subjects were required to fast for at least $10 \mathrm{~h}$ overnight and then receive a high-fat, high-calorie breakfast approximately $30 \mathrm{~min}$ before dosing in the morning of Day 1. During fasted study period, 
subjects were required to fast from 20:00 h on previous day until $4 \mathrm{~h}$ after dose on Day 1. Each dose of the study medication was administered at $08: 00 \mathrm{~h}$ and $30 \mathrm{~min}$ after starting breakfast during the fed study period. A sample for basal blood serum cortisol was drawn pre dose (0 min08:00 h) and further pharmacokinetic samples were drawn up to $24 \mathrm{~h}$ (every $30 \mathrm{~min}$ for $8 \mathrm{~h}$, every $60 \mathrm{~min}$ up to $16 \mathrm{~h}$ and every $120 \mathrm{~min}$ up to $24 \mathrm{~h}$ ).

In study period 3 (hydrocortisone fasted), dexamethasone-suppressed subjects ( $1 \mathrm{mg}$ dexamethasone administered at 22:00 h on Day 1, and at 06:00, 12:00 and $~ 18: 00$ h on Day 1) were admitted to the clinical unit on the previous day and remained until completion of all procedures (i.e. $12 \mathrm{~h}$ after dose). Subjects fasted from 20:00 h on previous day until $4 \mathrm{~h}$ after dose on Day 1 . Blood for serum cortisol were collected before dose $(0 \mathrm{~min}-08: 00 \mathrm{~h})$ and up to $12 \mathrm{~h}(15 \mathrm{~min}, 30 \mathrm{~min}, 45 \mathrm{~min}$, $1 \mathrm{~h}, 1.25 \mathrm{~h}, 1.5 \mathrm{~h}, 2 \mathrm{~h}, 2.5 \mathrm{~h}, 3 \mathrm{~h}, 4 \mathrm{~h}, 5 \mathrm{~h}, 6 \mathrm{~h}, 8 \mathrm{~h}, 10 \mathrm{~h}$ and $12 \mathrm{~h})$.

\section{Assays}

Cortisol was measured by LC-MS/MS using an Applied Biosystems MDS Sciex API365 mass spectrometer with Perkin Elmer Series 200 LC system with an electrospray source in negative ionization mode. Cortisol was measured in serum with the lower limit of quantitation (LLOQ) and upper limit of quantitation (ULOQ) of 0.50 and $250 \mathrm{ng} / \mathrm{mL}$ respectively. Reproducibility (relative standard deviation) $\mathrm{RSD} \%$ was equal to $<15 \%$ at the LLOQ QC (cortisol $0.50 \mathrm{ng} / \mathrm{mL}$ ) and $<10 \%$ at the low, medium and high QC level (cortisol 8, 30 and 200 ng/mL).

\section{Pharmacokinetics (PK)}

It was calculated from serum cortisol and derived free cortisol by non-compartmental analysis, using baselineadjusted concentrations. All calculations were done using WinNonlin Professional, version 5.3.

\section{Food effect and comparative bioavailability}

After logarithmictransformation, $\mathrm{C}_{\max }, \mathrm{AUC}_{0-\mathrm{t}}$ and $\mathrm{AUC}_{0-\text { inf }}$ values were subjected to a mixed effects analysis of variance (ANOVA) including fixed effects for sequence, period and treatment and a random effect for subject nested within sequence. Point estimates and 90\% confidence intervals (CI) were constructed for the contrasts between treatments using the residual mean square error obtained from the ANOVA. The point and interval estimates were then backtransformed to give estimates of the ratios of the geometric least squares means (LSmean) and corresponding 90\% CI. In addition, estimated geometric means were produced for each treatment. An assessment of $\mathrm{T}_{\max }$ was performed using the Wilcoxon matchedpairs test. In addition, a 95\% non-parametric CI was constructed for the median difference in $\mathrm{T}_{\max }$. Derived free cortisol was calculated for each sampling time point using the equation: $\mathrm{y}=3 \mathrm{E}-20 \mathrm{x}^{5}-1 \mathrm{E}-15 \mathrm{x}^{4}+1 \mathrm{E}-11 \mathrm{x}^{3}-$ $6 \mathrm{E}-08 \mathrm{x}^{2}+0.0002 \mathrm{x}+0.0306(\mathrm{x}=$ serum cortisol, $\mathrm{y}=$ derived free cortisol) (11). Serum cortisol and derived free cortisol were baseline adjusted using the 0 - $h$ sample for each subject, per treatment and values less than zero were set to zero. For calculation of derived PK parameters, concentrations below the lower limit of quantification were also assigned a value of zero.

\section{Ethics}

All human studies were approved by the South East Wales Research Ethics Committee, and all participants gave written informed consent. The study protocol was authorised by the Medicines and Healthcare products Regulatory Agency (MHRA).

\section{Results}

\section{In vitro impact of gastric $\mathrm{pH}$}

There was no significant drug release observed in $\mathrm{pH} 1.2$ and 4.5 dissolution media prior to the third and final $\mathrm{pH}$ change to $\mathrm{pH} 7.2$ media. The dissolution profiles of Chronocort 5 and $20 \mathrm{mg}$ modified-release capsules were comparable across the range of physiological $\mathrm{pH}$ conditions studied. All dissolution profiles were comparable to the standard Chronocort dissolution profile (Fig. 1) when assessed using the $f_{2}$ similarity test, with all values $>50$ ( $f_{2}:$ 80-95). Chronocort 5 and $20 \mathrm{mg}$ modified-release capsules continue to meet the compendial acceptance criteria for delayed-release dosage forms, demonstrating the integrity of the functional enteric coating was maintained in different acidic $\mathrm{pH}$ conditions and release of hydrocortisone was delayed until exposure to $\mathrm{pH} 7.2$ media (Fig. 1).

\section{In vitro impact of alcohol}

From 5 to $20 \% \mathrm{v} / \mathrm{v}$ of alcohol (ethanol) in the dissolution media, the obtained release profiles for Chronocort $20 \mathrm{mg}$ modified-release capsules were all comparable to the standard Chronocort dissolution profile when assessed 


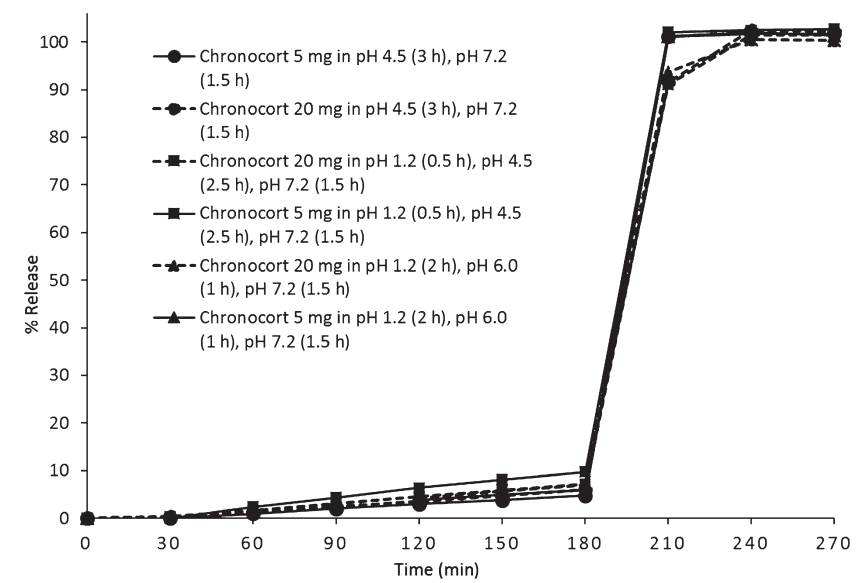

Figure 1

Chronocort 5 and $20 \mathrm{mg}$ capsules in vitro dissolution $(n=6)$, mean hydrocortisone release in three different $\mathrm{pH}$ media conditions: (i) pH 1.2 (2h), pH 6.0 (1 h), pH 7.2 (1.5h);

(ii) $\mathrm{pH} 1.2$ (0.5h), pH 4.5 (2.5h), pH 7.2 (1.5h); (iii) pH 4.5 (3h), $\mathrm{pH} 7.2$ (1.5h). (s.D. error is within each point).

using the $f_{2}$ similarity test, with all values $>50\left(f_{2}: 68-70\right)$. The Chronocort modified-release formulation retains its gastro-resistant, enteric properties in up to $20 \% \mathrm{v} / \mathrm{v}$ alcohol over $3 \mathrm{~h}$ until media $\mathrm{pH}$ is changed to 7.2 , triggering dissolution of the enteric coating and drug release (Fig. 2). A high concentration $40 \% \mathrm{v} / \mathrm{v}$ alcohol in the media led to a change in the dissolution profile, resulting in a value for the $f_{2}$ similarity test outside of the acceptance criteria. However, only a moderate increase in drug release was observed over the dissolution experiment, with $27 \%$ drug release after $30 \mathrm{~min}, 57 \%$ after $1 \mathrm{~h}, 81 \%$ after $1.5 \mathrm{~h}$ and $95 \%$ after $2 \mathrm{~h}$ ( $n=12$ samples). At the high $40 \% \mathrm{v} / \mathrm{v}$

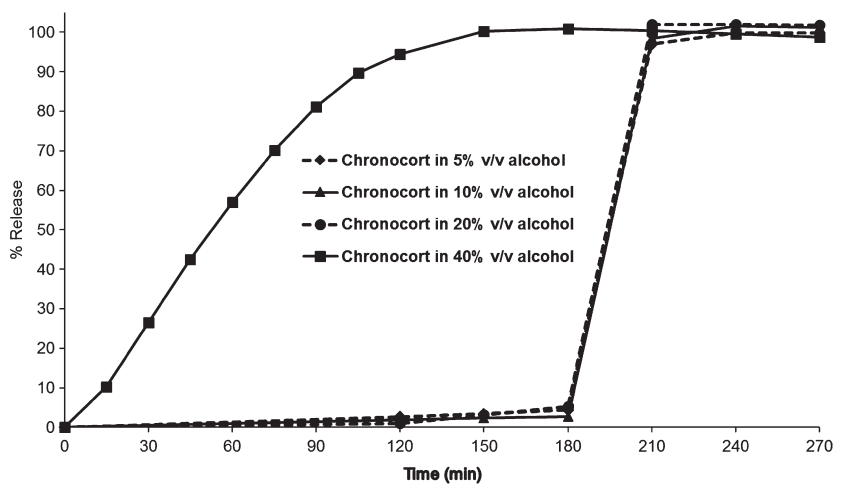

Figure 2

Chronocort $20 \mathrm{mg}$ capsules in vitro dissolution in alcoholic media $(n=12)$, mean hydrocortisone release in 5, 10, 20 or $40 \% \mathrm{v} / \mathrm{v}$ alcohol mixed in $\mathrm{pH} 1.2(2 \mathrm{~h}), \mathrm{pH} 6.0$ (1 h) and $\mathrm{pH} 7.2(1.5 \mathrm{~h})$ test conditions (s.D. error is within each point). alcohol concentration, the rate of drug release increases, albeit without any observed dose dumping (Fig. 2).

\section{In vivo PK analysis}

18 subjects who had concentrationtime profiles for 2 treatments and adequately suppressed pre-dose cortisol $(<60 \mathrm{nmol} / \mathrm{L})$ were included in the PK population. Hydrocortisone profiles of 4 subjects were excluded from the PK analysis of immediate-release hydrocortisone; two subjects did not suppress on one occasion each, one subject did not receive hydrocortisone tablets due to an adverse event after dexamethasone, one did not have a baseline sample performed.

\section{Food effect on Chronocort}

The rate of hydrocortisone absorption from Chronocort was reduced and delayed when administered in fed state (after a high-fat, high-calorie breakfast) when compared to the fasted state, as reflected by a lower $\mathrm{C}_{\max }$ $(549.49 \mathrm{nmol} / \mathrm{L}$ vs $708.46 \mathrm{nmol} / \mathrm{L}$ geometric LSmean ratio $77.56 \%$ with $90 \%$ C.I. 70.89-84.86\%) and longer $\mathrm{T}_{\max }$ (6.75 h vs 4.5 h, $P=0.0005$ ) (Fig. 3 and Table 1 ). Geometric LSmean of $\mathrm{AUC}_{0-\mathrm{t}}$ and $\mathrm{AUC}_{0-\mathrm{inf}}$ were similar during fed (3229.26 and 2980.85 h*nmol/L) and fasted (3273.59 and $2985.31 \mathrm{~h}$ (nmol/L) study periods and the fed/fasted ratio CIs were within $80.0-125.0 \%$ indicating that the overall exposure to hydrocortisone was similar during fed and fasted periods. The $t_{1 / 2}$ was the same for fed and fasted Chronocort administration at $1.38 \mathrm{~h}$, and CL/F was similar at 16.70 and $18.48 \mathrm{~L} / \mathrm{h}$, respectively.

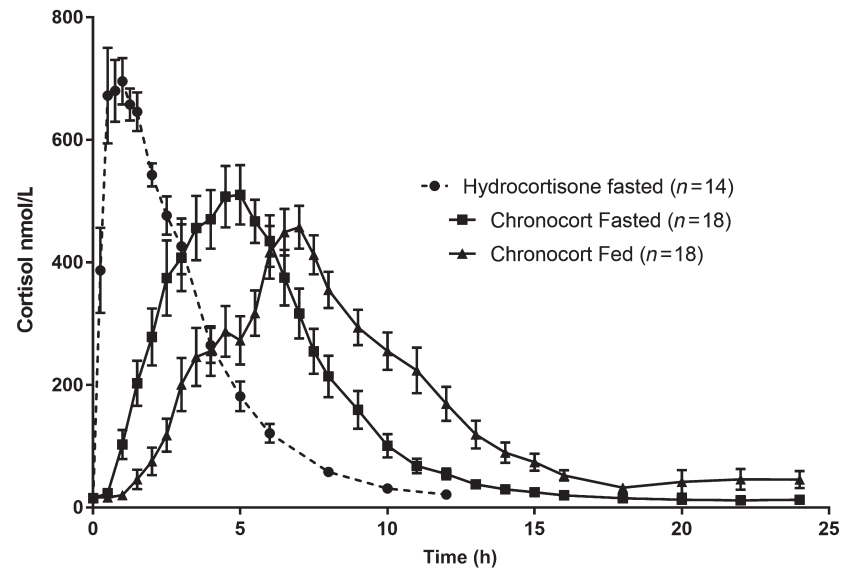

Figure 3

Mean (S.E.M.) cortisol concentration after immediate-release hydrocortisone fasted and Chronocort fasted and fed in healthy volunteers. 
Table 1 Summary of the statistical analysis of food effect on Chronocort PK for serum cortisol (baseline adjusted) (PK population).

\begin{tabular}{|c|c|c|}
\hline \multirow[b]{2}{*}{ PK parameter } & \multicolumn{2}{|c|}{ IMPs: 20 mg hydrocortisone } \\
\hline & Chronocort (fed) $(n=18)^{*}$ & Chronocort (fasted) $(n=18)^{*}$ \\
\hline $\mathrm{C}_{\max }(\mathrm{nmol} / \mathrm{L})$ & 549.49 & 708.46 \\
\hline$A \cup C_{0-t}(h * n m o l / L)$ & 3229.26 & 2980.85 \\
\hline $\mathrm{AUC}_{0-\mathrm{inf}}\left(\mathrm{h}{ }^{*} \mathrm{nmol} / \mathrm{L}\right)$ & 3273.59 & 2985.31 \\
\hline $\mathrm{T}_{\max }(\mathrm{h})$ & $6.75^{\dagger}$ & $4.5^{+}$ \\
\hline
\end{tabular}

\begin{tabular}{c} 
Chronocort fed vs Chronocort fasted * * $^{*}$ \\
\hline $77.56(70.89-84.86)$ \\
$108.33(102.30-114.72)$ \\
$109.66(103.19-116.53)$ \\
$2.25(1.25-3.75)(0.0005)^{\dagger \dagger}$
\end{tabular}

*Geometric LS mean; **Geometric LS mean $(90 \% \mathrm{Cl}) ;{ }^{\dagger}$ Median; ${ }^{\dagger+}$ Median difference $(95 \% \mathrm{Cl})(P$ value $)$

\section{Comparative bioavailability of Chronocort vs hydrocortisone tablets-fasted}

For serum cortisol, the geometric LSmean and test/reference ratio indicate that Chronocort is more bioavailable than the hydrocortisone tablets (Table 2). Overall exposure $\left(\mathrm{AUC}_{0-\mathrm{t}}\right.$ and $\mathrm{AUC}_{0-\text { inf }}$ ) is approximately $19 \%$ higher for Chronocort, as reflected by geometric LSmean ratios of approximately $119 \%$. When compared to hydrocortisone tablets, the rate of absorption is also reduced and delayed after administration of Chronocort as reflected by a lower $\mathrm{C}_{\max }(708.46 \mathrm{nmol} / \mathrm{L}$ vs $850.82 \mathrm{nmol} / \mathrm{L}$, Geometric LSmean Ratio $74.75 \%$ with $90 \%$ CI of $64.08-87.19 \%)$ and longer $\mathrm{T}_{\max }$ ( $4.5 \mathrm{~h}$ vs $0.88 \mathrm{~h}, P=0.0014$ ). The $\mathrm{t}_{1 / 2}$ was similar for Chronocort and hydrocortisone tablets at 1.38 and $1.40 \mathrm{~h}$ respectively. The $\mathrm{CL} / \mathrm{F}$ appears to be higher for the hydrocortisone tablets when compared to Chronocort at 22.24 and $18.48 \mathrm{~L} / \mathrm{h}$ respectively. Analysis of derived free cortisol suggests Chronocort exposure was within 80.0-125.0\% CIs based on $\mathrm{AUC}_{0-\mathrm{t}}$ and $\mathrm{AUC}_{0 \text {-inf }}$ (Table 3).

\section{Discussion}

Chronocort modified-release in vitro dissolution was neither affected by prolonged exposure to gastric dissolution media up to $\mathrm{pH} 6.0$ nor by an alcohol content up to $20 \% \mathrm{v} / \mathrm{v}$, demonstrating that the polymer system used to provide the delayed release functionality affords a robust enteric performance without resulting in premature coat dissolution or affecting the downstream release of hydrocortisone. Taking Chronocort with food delayed and reduced the cortisol $\mathrm{C}_{\max }$ but did not affect the overall cortisol exposure. Chronocort showed greater comparative bioavailability when compared to immediaterelease hydrocortisone although this was within 80-125\% CIs when adjusted for protein binding.

Gastric $\mathrm{pH}$ in healthy individuals may vary between $\mathrm{pH} 1.0$ and 2.5 preprandial and then increases as food is ingested to reach a $\mathrm{pH}$ of $\leq 5.0$ before returning to normal gastric $\mathrm{pH}$ values; after gastric emptying, medication passes through the small intestine where $\mathrm{pH}$ values in the distal ileum are reported to vary between $\mathrm{pH} 6.5$ and $8.0(12,13)$. Chronocort was designed to release hydrocortisone in the last third of the small bowel to allow for delayed and sustained absorption (6). The multiparticulate formulation approach was selected to provide more predictable, reproducible gastrointestinal transit over single-unit oral dosage forms (14). To achieve its release profile, the multi-particulate beads of Chronocort are coated with the polymer EUDRAGIT (S100/L100) designed to dissolve at $\mathrm{pH} \geq 6.8$. Our data presented here demonstrate that the enteric coat does not dissolve at $\mathrm{pH}$ values $\leq 6.0$ and drug release only occurs above the enteric coat $\mathrm{pH} 6.8$ trigger point. This is of importance suggesting that there should not be a problem taking Chronocort with concomitant medication that raises gastric $\mathrm{pH}$, such as proton pump inhibitors where the gastric $\mathrm{pH}$ can typically rise above 4.0 but not $>$ than $\mathrm{pH} 6.0(15,16)$.

Table 2 Summary of the statistical analysis of bioavailability between chronocort and hydrocortisone tablets (fasted) for serum cortisol (baseline adjusted) (PK population).

\begin{tabular}{|c|c|c|c|}
\hline \multirow[b]{2}{*}{ PK parameter } & \multicolumn{2}{|c|}{ IMPs: 20 mg hydrocortisone } & \multirow{2}{*}{$\begin{array}{l}\text { Chronocort fasted vs hydrocortisone } \\
\text { tablets fasted** }\end{array}$} \\
\hline & Chronocort (fasted) $(n=18)$ * & Hydrocortisone tablets (fasted) $(n=14) *$ & \\
\hline $\mathrm{C}_{\max }(\mathrm{nmol} / \mathrm{L})$ & 708.46 & 850.82 & $83.27(75.58-91.74)$ \\
\hline $\mathrm{AUC}_{0-\mathrm{t}}(\mathrm{h} * \mathrm{nmol} / \mathrm{L})$ & 2980.85 & 2508.52 & $118.83(111.58-126.54)$ \\
\hline $\mathrm{AUC}_{0-\mathrm{inf}}(\mathrm{h} * \mathrm{nmol} / \mathrm{L})$ & 2985.31 & 2510.82 & $118.90(111.58-126.69)$ \\
\hline $\mathrm{T}_{\max }(\mathrm{h})$ & $4.5^{\dagger}$ & $0.88^{\dagger}$ & $3.50(2.25-4.38)(0.0014)^{\dagger \dagger}$ \\
\hline
\end{tabular}


Table 3 Summary of the statistical analysis of bioavailability between chronocort and hydrocortisone tablets (fasted) for derived free cortisol (baseline adjusted) (PK population).

\begin{tabular}{|c|c|c|}
\hline \multirow[b]{2}{*}{ PK parameter } & \multicolumn{2}{|c|}{ IMPs: 20 mg hydrocortisone } \\
\hline & Chronocort (fasted) $(n=18)^{*}$ & Hydrocortisone tablets (fasted) $(n=14)^{*}$ \\
\hline $\mathrm{C}_{\max }(\mathrm{nmol} / \mathrm{L})$ & 106.06 & 141.89 \\
\hline $\mathrm{AUC}_{0-\mathrm{t}}(\mathrm{h} * \mathrm{nmol} / \mathrm{L})$ & 326.87 & 289.96 \\
\hline$A \cup C_{0-\text { inf }}(\mathrm{h} * \mathrm{nmol} / \mathrm{L})$ & 327.03 & 290.36 \\
\hline$T_{\max }(h)$ & $4.5^{\dagger}$ & $0.88^{\dagger}$ \\
\hline
\end{tabular}

$\begin{gathered}\text { Chronocort fasted vs hydrocortisone } \\ \text { tablets fasted * }\end{gathered}$
$74.75(64.08-87.19)$
$112.73(105.33-120.65)$
$112.63(105.39-120.36)$
$3.50(2.25-4.38)(0.0014)^{\dagger \dagger}$

${ }^{*}$ Geometric LS mean; ${ }^{*}$ Geometric LS mean $(90 \% \mathrm{Cl}) ;{ }^{\dagger}$ Median; ${ }^{\dagger \dagger}$ Median difference $(95 \% \mathrm{Cl})(P$ value $)$.

Alcohol can influence drug absorption from modifiedrelease dosage forms and potentially on the dissolution of the enteric coating of drugs (17). Concomitant consumption of alcoholic beverages with such products may induce dose dumping (18). We examined the effect of alcohol on the dissolution of Chronocort as it is designed to be taken last thing at night to provide the overnight rise in cortisol, and in many cultures, it is common to have alcohol in the evening. From 5 to $20 \% \mathrm{v} / \mathrm{v}$ of alcohol, there was no effect of alcohol on hydrocortisone release confirming that Chronocort meets the EMA regulatory guidelines for alcohol testing of modified-release dosage forms (18). At a high alcohol concentration of $40 \% \mathrm{v} / \mathrm{v}$ recommended in the FDA guideline for testing (19), there was a change in the Chronocort dissolution profile observed, with a moderate increase in drug release over the $2 \mathrm{~h}$ but no significant alcohol-induced dose dumping. The conclusion from this study, is that dissolution of Chronocort modifiedrelease capsules are not perturbed by alcohol under typical consumption levels and shows no dose dumping. The strongest alcoholic spirits generally available for consumption are ca. $40 \% \mathrm{v} / \mathrm{v}$ alcohol which on ingestion would be very rapidly diluted to $<20 \% \mathrm{v} / \mathrm{v}$ in the stomach. It has been calculated that to achieve a $40 \% \mathrm{v} / \mathrm{v}$ alcohol concentration in the stomach would require the intake into an empty stomach of $240 \mathrm{~mL}$ of an alcoholic beverage with $56 \% \mathrm{v} / \mathrm{v}$ alcohol content, based on $100 \mathrm{~mL}$ gastric fluid (20). Furthermore, hydrocortisone has a wide therapeutic index and long established safety profile, lowering the risk profile for Chronocort modifiedrelease capsules. For example, for some indications, i.e. asthma and COPD, doses up to $500 \mathrm{mg}$ are used. Therefore, the concomitant consumption of alcoholic beverages presents no risk for Chronocort dose dumping.

Food is known to slow the absorption of many drugs as it slows gastric emptying and gut transit (14). We found that a high-fat, high-calorie meal delayed absorption of Chronocort but did not alter the overall cortisol exposure.
For immediate-release hydrocortisone, the evidence shows that food delays the $\mathrm{C}_{\max }$ and increases exposure (7), and the same thing was true for the dual-release formulation of hydrocortisone Plenadren (10). The median time of $\mathrm{T}_{\max }$ for Chronocort given with food was $6.75 \mathrm{~h}$ and when fasted was $4.5 \mathrm{~h}$. We have previously published data that shows when Chronocort $20 \mathrm{mg}$ was given at 23:00 h at night a median $\mathrm{T}_{\max }$ of $6 \mathrm{~h}$ was achieved, similar to that when Chronocort $20 \mathrm{mg}$ was taken in the morning with food. It is likely that a night-time dose has a delayed $\mathrm{T}_{\max }$ despite being without food due to increased gastric residence and slower gut motility during sleep (21). It is likely in clinical practice that patients will take Chronocort in the morning close to food, and this may give a delayed $\mathrm{T}_{\max }$ but will not increase exposure to cortisol.

Comparative bioavailability showed that Chronocort taken in fasted state gave greater cortisol exposure than immediate-release hydrocortisone, but when adjusted for protein binding, they gave similar cortisol exposure. This would be predicted as serum cortisol is highly protein bound and binding to plasma proteins is non-linear with higher plasma concentrations having a greater unbound fraction than lower concentrations (11), and the unbound fraction having more rapid clearance (22). When taking $20 \mathrm{mg}$ immediate-release hydrocortisone, the $\mathrm{C}_{\max }$ exceeds the binding capacity of cortisol-binding protein at a concentration of $\sim 550 \mathrm{nmol} / \mathrm{L}$, the free cortisol is more quickly cleared than the bound fraction and therefore the cortisol AUC for total cortisol is lower than it would be if it had not exceeded the binding capacity (11). In contrast, Chronocort gives a $\mathrm{C}_{\max }$ that is comparable to healthy subjects, and there is not such a great free portion although with its sustained absorption, the free cortisol exposure over time is similar to immediate release hydrocortisone. Thus, Chronocort, designed with a robust enteric coat, is unaffected by normal physiological $\mathrm{pH}$ and alcohol conditions encountered in normal daily life whilst providing cortisol replacement to levels which are similar to those found in healthy individuals. 
Declaration of interest

$\mathrm{R} J \mathrm{R}$ and $\mathrm{M} \mathrm{J} \mathrm{W}$ are directors and $\mathrm{DN} \mathrm{M}$ and $\mathrm{G} \mathrm{N}$ are employees of Diurnal Ltd.

\section{Acknowledgements}

This study was initiated and funded by Diurnal Ltd.

\section{References}

1 Debono M, Ghobadi C, Rostami-Hodjegan A, Huatan $\mathrm{H}$ Campbell MJ, Newell-Price J, Darzy K, Merke DP, Arlt W \& Ross RJ. Modified-release hydrocortisone to provide circadian cortisol profiles. Journal of Clinical Endocrinology and Metabolism 200994 1548-1554. (doi:10.1210/jc.2008-2380)

2 Simon N, Castinetti F, Ouliac F, Lesavre N, Brue T \& Oliver C. Pharmacokinetic evidence for suboptimal treatment of adrenal insufficiency with currently available hydrocortisone tablets. Clinical Pharmacokinetics 201049 455-463. (doi:10.2165/11531290000000000-00000)

3 Han TS, Walker BR, Arlt W \& Ross RJ. Treatment and health outcomes in adults with congenital adrenal hyperplasia. Nature Reviews Endocrinology 201410 115-124. (doi:10.1038/nrendo.2013.239)

4 Lovas K \& Husebye ES. Continuous subcutaneous hydrocortisone infusion in Addison's disease. European Journal of Endocrinology 2007 157 109-112. (doi:10.1530/EJE-07-0052)

5 Johannsson G, Bergthorsdottir R, Nilsson AG, Lennernas H, Hedner T \& Skrtic S. Improving glucocorticoid replacement therapy using a novel modified-release hydrocortisone tablet: a pharmacokinetic study. European Journal of Endocrinology 2009161 119-130. (doi:10.1530/EJE-09-0170)

6 Whitaker MJ, Debono M, Huatan H, Merke DP, Arlt W \& Ross RJ. An oral multiparticulate, modified-release, hydrocortisone replacement therapy that provides physiological cortisol exposure. Clinical Endocrinology 201480 554-561. (doi:10.1111/cen.12316)

7 Mah PM, Jenkins RC, Rostami-Hodjegan A, Newell-Price J, Doane A, Ibbotson V, Tucker GT \& Ross RJ. Weight-related dosing, timing and monitoring hydrocortisone replacement therapy in patients with adrenal insufficiency. Clinical Endocrinology 200461 367-375. (doi:10.1111/j.1365-2265.2004.02106.x)

8 Aanderud S \& Myking OL. Plasma cortisol concentrations after oral substitution of cortisone in the fasting and nonfasting state. Acta Medica Scandinavica 1981210 157-161. (doi:10.1111/j.0954-6820.1981.tb09794.x)
9 Johannsson G, Nilsson AG, Bergthorsdottir R, Burman P, Dahlqvist P, Ekman B, Engstrom BE, Olsson T, Ragnarsson O, Ryberg $\mathrm{M}$ et al. Improved cortisol exposure-time profile and outcome in patients with adrenal insufficiency: a prospective randomized trial of a novel hydrocortisone dual-release formulation. Journal of Clinical Endocrinology and Metabolism 201297 473-481. (doi:10.1210/jc.2011-1926)

10 Duocort. Plenadren. European Public Assessment Reports 2011 EMEA/ $\mathrm{H} / \mathrm{C} / 2185$.

11 Lentjes EG \& Romijn FH. Temperature-dependent cortisol distribution among the blood compartments in man. Journal of Clinical Endocrinology and Metabolism 199984 682-687. (doi:10.1210/jcem.84.2.5461)

12 Charman WN, Porter CJ, Mithani S \& Dressman JB. Physiochemical and physiological mechanisms for the effects of food on drug absorption: the role of lipids and pH. Journal of Pharmaceutical Sciences 199786 269-282. (doi:10.1021/js960085v)

13 Evans DF, Pye G, Bramley R, Clark AG, Dyson TJ \& Hardcastle JD. Measurement of gastrointestinal $\mathrm{pH}$ profiles in normal ambulant human subjects. Gut 198829 1035-1041. (doi:10.1136/gut.29.8.1035)

14 Roy P \& Shahiwala A. Multiparticulate formulation approach to pulsatile drug delivery: current perspectives. Journal of Controlled Release 2009134 74-80. (doi:10.1016/j.jconrel.2008.11.011)

15 Sanaka M, Yamamoto T \& Kuyama Y. Effects of proton pump inhibitors on gastric emptying: a systematic review. Digestive Diseases and Sciences 201055 2431-2440. (doi:10.1007/s10620-009-1076-x)

16 Rasmussen L, Oster-Jorgensen E, Qvist N \& Pedersen SA. The effects of omeprazole on intragastric $\mathrm{pH}$, intestinal motility, and gastric emptying rate. Scandinavian Journal of Gastroenterology 199934 671-675. (doi:10.1080/003655299750025868)

17 Meyer RJ \& Hussain AS. Mitigating the risks of ethanol induced dose dumping from oral sustained/controlled release dosage forms. FDA's ACPS Meeting 2005 1-4.

18 EMA. Guideline on the pharmacokinetic and clinical evaluation of modified release dosage forms EMA/CPMP/EWP/280/96 Corr1 2015

19 FDA. Guideline: Quality by Design for ANDAs: An Example for Modified Release Dosage Forms 2011.

20 Friebe TP, Asgarzadeh F, Gray A, Hughes K, Hebestreit J-P, Rosiaux Y, Yunis M \& Faham A. Regulatory considerations for alcohol-induced dose dumping of oral modified-release formulations. Pharmaceutical Technology 201538 40-46.

21 Coupe AJ, Davis SS, Evans DF \& Wilding IR. Nocturnal scintigraphic imaging to investigate the gastrointestinal transit of dosage forms. Journal of Controlled Release 199220 155-162. (doi:10.1016/01683659(92)90161-J)

22 Perogamvros I, Aarons L, Miller AG, Trainer PJ \& Ray DW. Corticosteroid-binding globulin regulates cortisol pharmacokinetics. Clinical Endocrinology 201174 30-36. (doi:10.1111/j.13652265.2010.03897.x)

Received 19 November 2016

Revised version received 11 January 2017

Accepted 17 January 2017 